\title{
Epistemologia das concepções abertas no ensino da educação física: o legado de Jean Piaget
}

Joaquim Francisco Lira Neto

Mestre em Educação pela Unicamp e Professor da REE/SP

\section{Resumo}

O presente trabalho tem o objetivo de analisar a influência do pensamento de Jean Piaget (1896-1980) na proposta das Concepções Abertas no ensino da Educação Física. A epistemologia do autor constituiu uma das referências para a proposta em questão, o que torna necessário o estudo dos pressupostos gnosiológicos e ontológicos da teoria piagetiana para a melhor compreensão das implicações político-pedagógicas do ensino aberto. É possível identificar problemas e limitações das Concepções Abertas, que, por herdar as visões de homem e sociedade defendidas por Piaget, encontra-se presa aos parâmetros do ensino centrado no aluno.

Palavras-chave: Educação Física Escolar; Piaget; Epistemologia.

\begin{abstract}
This paper aims to analyze the influence of the Piaget's thought in the proposal of Open Conceptions in the teaching of Physical Education. The epistemology of the author was one of the references to the proposal in question, which calls for the study of epistemological and ontological assumptions of piagetian theory for better understanding of the political and pedagogical implications of open education. It's possible to identify problems and limitations of Open Conceptions, which, by inheriting the visions of man and society advocated by Piaget, is attached to the parameters of education focused on students.
\end{abstract}

Keywords: School Physical Education; Piaget; Epistemology. 


\section{Introdução}

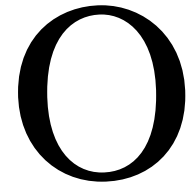

presente trabalho tem como objetivo analisar a influência que os estudos de Jean Piaget (1896-1980) exerceram sobre a proposta das Concepções Abertas no ensino da Educação Física.

Primeiramente, serão expostos os aspectos mais gerais das Concepções Abertas que podem ser relacionados com a epistemologia genética piagetiana. Posteriormente, serão expostos os pressupostos gnosiológicos e ontológicos dos quais Piaget parte, para que, finalmente, seja feita uma crítica às suas implicações político-pedagógicas.

O que justifica a elaboração deste trabalho é a possibilidade de se obter um aprofundamento na compreensão de determinados aspectos da proposta da Educação Física aqui estudada, através da análise de suas relações com o pensamento de Piaget. Tal aprofundamento é necessário para evidenciar limitações da referida proposta.

\section{Sobre as concepções abertas}

A proposta das Concepções Abertas no ensino da Educação Física foi introduzida no Brasil no início da década de 1980 pelos professores Jürgen Dieckert e Reiner Hildebrandt-Stamann.

Entre as referências dos autores para a elaboração de sua proposta estão o filósofo Merleau-Ponty, os psicólogos da Gestalt, Paulo Freire e Jean Piaget. Serão analisados aqui os aspectos das Concepções Abertas que demonstram forte influência da gnosiologia e da ontologia piagetianas.

$\mathrm{Na}$ tentativa de superar o ensino de movimentos esportivos padronizados nas aulas de Educação Física, a proposta das Concepções Abertas defende um ensino centrado nas experiências que os alunos realizam; um ensino que valorize os interesses deles, bem como o seu papel ativo na assimilação dos conteúdos. Nesta perspectiva, a aula deve ser aberta às elaborações individuais dos alunos.

Partindo-se do pressuposto de que "o homem não entra no mundo pelo intelecto, mas por seu corpo" (Hildebrandt-Stramann, 2004, p. 25), deve 
haver um espaço privilegiado nas aulas de Educação Física para que os objetos externos ao corpo sejam assimilados às atividades dos alunos, através da criação de experiências motoras ricas e estimulantes.

Quanto à influência de Piaget, Hildebrandt-Stramann (2004, p. 25) escreve:

Piaget (1978) caracteriza este processo da constituição das experiências com os termos da acomodação e da assimilação. Ele explica bem claro que o sujeito não faz novas experiências pela recepção passiva, mas somente num processo dialético ativo. Nesse processo da acomodação e da assimilação, o sujeito ganha experiência, experiência sobre si mesmo e sobre as coisas do mundo. Neste processo o sujeito ganha uma identidade.

Em um outro trabalho (Lira Neto, 2008), no qual foram estabelecidas possíveis relações entre as Concepções Abertas e o método Paulo Freire, foram enunciados alguns dos aspectos da proposta em questão, referentes à subjetivação do ensino. Entre eles está a restrição às intervenções do professor, que, embora não se deva ausentar completamente de todas as aulas, deve ter um espaço de ação limitado, para que não prejudique a interação e o desabrochar das subjetividades dos alunos.

Nesta perspectiva, as atividades de ensino-aprendizagem devem ser construídas conjuntamente, o que é chamado de "co-decisão" (HildebrandtStramann e Laging, 1986, P. 11). O professor exerce uma ação mediadora no sentido de apenas coordenar as situações de ensino, estimulando a participação dos alunos.

Tal ação ocorre através da colocação de "situações-problema ou situações de conflito" (Hildebrandt-Stramann e Laging, 1986, p. 21). Assim, os alunos são incentivados a resolver um determinado desafio que requer a construção de movimentos, que - por ser uma situação ampla que permite múltiplas respostas para a sua solução - carregam os significados subjetivos das interpretações fornecidas por cada um dos alunos.

$\mathrm{Na}$ proposta das Concepções Abertas, a experiência torna-se uma "categoria central na teoria didática das aulas abertas" (HildebrandtStramann, 2005, p. 79). A experiência vai além da recepção dos dados da realidade até a reformulação dos mesmos pela atividade do sujeito. A 
questão fundamental aqui é a de que o professor pode prejudicar tal atividade com intervenções excessivas, limitando o espaço de interpretação dos dados objetivos pelos alunos.

Desta forma, na proposta das Concepções Abertas opera-se uma dicotomia entre aulas centradas no professor e aulas centradas nos alunos. Isto fica explícito quando Hildebrandt-Stramann (2005, p.141) afirma, primeiramente, que: "sob a concepção de aulas fechadas podemos resumir as concepções de aulas orientadas: no professor, no produto; nas metas definidas e na intenção racionalista". E, posteriormente: "sob a concepção de aulas abertas, podemos resumir as concepções de aulas orientadas: no aluno, no processo, na problematização e na comunicação".

Devido à contradição entre professor e alunos, a forma de ensino deve ser não-diretiva. Apoiando-se em Jost (apud Hildebrandt-Stramann e Laging, 1986, p. 25), para quem métodos não-diretivos são "aqueles que contribuem para levar em conta as ideias e intenções dos alunos e para promover sua autonomia em interações conscientemente inseridas". $\mathrm{Na}$ proposta das Concepções Abertas é defendido que:

[...] o professor de Educação Física que quer abrir o ensino para seu "contexto social", que quer estimular seus alunos a maior independência e espontaneidade, que quer fazer de suas próprias reflexões e intenções o padrão para a formação do ensino, precisa procurar "formas não-diretivas" da situação (Hildebrandt-Stramann e Laging, 1986, p. 25).

Os autores da proposta defendem que deve haver apenas um pequeno espaço para a diretividade, destinado à intervenção do professor nos problemas que os alunos de forma alguma conseguiriam solucionar sozinhos. Além deste espaço, é defendido na proposta que o professor deve coordenar reflexões com os alunos sobre ideias e valores que permeiam a vivência de elementos da cultura corporal.

São exemplos de situações em que a diretividade é realmente necessária: "constantes brigas pelo lugar na fila e pela duração de um exercício, perigos de lesões sérias, sub ou supersolicitações condicionadas às tarefas" (Hildebrandt-Stramann e Laging, 1986, p. 25). Os autores são enfáticos ao dizer que "uma direção mais forte por parte do professor é 
apenas passageira e poderá ter como objetivo a abertura do ensino renovada para a co-determinação dos alunos" (Hildebrandt-Stramann e Laging, 1986, P. 25).

Na obra Concepções Abertas no ensino da Educação Física há um espaço destinado a exemplos de aulas ministradas por professores da disciplina em questão que, após reuniões, "declararam-se prontos a colaborar com os autores neste tipo de ensino aberto em Educação Física" (Hildebrandt-Stramann e Laging, 1986, p. 47). Como os exemplos foram escolhidos para compor a obra de modo a ilustrar a proposta das Concepções Abertas, supõe-se serem fiéis à mesma.

Após uma de suas aulas, descritas no livro, a professora Gerlinde Glatzer, referindo-se à intensidade de suas intervenções, afirma:

Para a unidade de aula, formulo uma colocação de objetivo abrangente: os alunos deverão trazer suas necessidades para a aula e transformá-las. Assim eles aprendem a participar da turma ou de pequenos grupos, a formular acordos, a elaborar regulamentações para o tratamento em comum, a debater problemas e a procurar, autonomamente, soluções. Para a realização destes objetivos é necessário, a meu ver, que os alunos auto e co-determinem o processo de aprendizagem no que se refere a conteúdos e organização. Com isso, o poder de decisão do professor deve ser reduzido em favor da competência de decisão dos alunos. A determinação de conteúdo não parte de mim. A decisão sobre o conteúdo de uma unidade de aula é encontrada numa aula de "Comportamento Social". Os alunos citam quase que exclusivamente jogos de bola, tanto os grandes jogos competitivos, como os pequenos jogos e formas de jogo. Por razões de tempo, não há concretizações. Como não quero tomar nenhuma decisão - o que limitaria os alunos - faço, na primeira aula, uma oferta aberta com diferentes bolas (bolas de vôlei, de basquete, de tênis de mesa, medicinebóis). Não ofereço bolas de futebol nem de handebol, para não reforçar a fixação nestes dois jogos (Glatzer, 1986, p. 69-70).

É patente como, para a professora, há uma contradição entre as suas intervenções e a liberdade, a autonomia dos alunos, o que exige um ensino não-diretivo. Ela chega a se isentar da determinação dos conteúdos de uma unidade de aula. É interessante notar que ela deseja transformar as inclinações iniciais dos alunos, mas, como considera a diretividade perniciosa, recorre - talvez como última alternativa - à ocultação de alguns materiais didáticos por saber que apetecem os alunos de forma a restringir 
suas escolhas. Como ela mesma afirma, o seu poder de decisão deve ser reduzido em favor da competência de decisão dos alunos.

Mais adiante na obra, há outra fala da professora bastante elucidativa sobre como deve ser a relação entre professor e alunos nas Concepções Abertas:

No início da unidade de ensino eu me sentia insegura quanto às situações em que poderia atuar como professora num ensino de Educação Física de concepção aberta. A atuação não deveria ser compreendida como "direção" no sentido de prescrever. Minhas inseguranças (abertura de conteúdo e organizacional, intensidade do som, desdobramento, desordem, os alunos aprendem o suficiente?...) diminuíram com a crescente duração da unidade de ensino. Aprendi a reconhecer situações no processo de ensino nas quais eu atuava estimulando e aconselhando, quando os alunos precisavam de minha ajuda para a superação de seus problemas. Isto me deu a possibilidade de assumir iniciativas e de me introduzir, mais como parceira, no processo. Saí fortalecida na minha concepção de que, no ensino do esporte, é preciso avaliar mais e mais, indo de encontro às necessidades dos alunos. Para alcançar uma transformação satisfatória, as decisões devem ser tomadas e assumidas por alunos e professor em conjunto. Motivação, colaboração, cooperação e sobretudo satisfação foram os resultados da unidade de ensino assim concebida (Glatzer, 1986, p. 106).

Desta forma, na proposta das Concepções Abertas, o professor deve reduzir a sua diretividade, passando apenas a coordenar, animar, estimular, aconselhar as ações dos alunos, e nunca buscar o rompimento de interesses já apresentados por eles. Através da co-decisão, da cooperação entre professor e alunos, assim como entre alunos, acredita-se que serão formados indivíduos autônomos, criativos e mais cooperativos.

Após a apresentação dos aspectos mais gerais das Concepções Abertas, torna-se necessária a explicitação dos pressupostos gnosiológicos e ontológicos piagetianos que fundamentam a proposta em questão.

\section{Jean Piaget nas concepções abertas}

Jean Piaget (1896-1980) foi um pesquisador cujo trabalho trouxe grandes contribuições para diversas áreas do conhecimento, como a Psicologia, a Filosofia, a Pedagogia e a Educação Física.

Alguns de seus textos - como os reunidos nas coletâneas Psicologia e pedagogia (Piaget, 1976), Para onde vai a educação (Piaget, 1996) e Sobre 
a pedagogia (Piaget, 1998) - dirigem-se diretamente à educação. Além destes, há uma série de trabalhos que Piaget desenvolveu com o auxílio de colaboradores que, mesmo não tratando diretamente da educação, contribuíram para o fomento de reflexões pedagógicas.

O pensamento de Piaget, que tem influenciado significativamente a produção científica na Educação Física, parte de pressupostos gnosiológicos e ontológicos que devem ser analisados para uma melhor compreensão de suas implicações político-pedagógicas. Isto porque, como diz Sánchez Gamboa (2007, p. 58):

$\mathrm{Na}$ recuperação das inter-relações entre os pressupostos epistemológicos e gnosiológicos com as concepções do real (categorias ontológicas) podemos desvendar as implicações filosóficas e ideológicas de um determinado modelo de pesquisa científica e assim também elucidar as profundas relações entre conhecimento e interesse.

No que se refere aos pressupostos gnosiológicos, Piaget identificou, ao longo da ontogênese, determinados estágios ou etapas que representam o desenvolvimento de estruturas cognitivas auto-reguladas, que se sucedem através de um processo dialético no qual as etapas anteriores são suprasumidas pelas posteriores.

A inteligência é, para o autor, uma função que possibilita o processo dinâmico de adaptação do sujeito ao meio em que vive, sendo que tal processo depende da interação de dois mecanismos: de assimilação, através do qual novos elementos são incorporados às estruturas já existentes no sujeito, e de acomodação, que significa a reorganização das estruturas internas do sujeito em virtude dos elementos do exterior que foram assimilados.

Desta forma, os estágios sensório-motor, pré-operatório, operatório concreto e operatório formal (ou hipotético-dedutivo), representam estruturas equilibradas em níveis gradativamente superiores, que expressam o desenvolvimento cognitivo do sujeito, que progride do inicial egocentrismo à socialização.

Piaget, ao analisar as pesquisas psicológicas acerca do desenvolvimento da inteligência e das estruturas cognitivas, afirma que três 
perspectivas podem ser identificadas. A primeira delas, empirista, reduz todo o conhecimento a aquisições exógenas, provenientes da experiência ou de exposições dirigidas pelo adulto. A segunda, inatista, influenciada pelo linguista Chomsky, que acredita na existência de "um 'núcleo fixo inato', determinante das estruturas iniciais da linguagem, tal como a relação entre sujeito e predicado" (Piaget, 1996, p. 10). Por fim, Piaget descreve a perspectiva por ele defendida:

A terceira direção, que é decididamente a nossa (e que nos leva a atribuir os começos da linguagem às estruturas construídas pela inteligência sensorialmotora preexistente), é de natureza construtivista, isto é, sem preformação exógena (empirismo) ou endógena (inatismo) por contínuas ultrapassagens das elaborações sucessivas, o que, do ponto de vista pedagógico, leva incontestavelmente a dar toda ênfase às atividades que favoreçam a espontaneidade da criança (Piaget, 1996, p. 10-11).

Está explícita a relação direta que Piaget estabelece entre o resultado de suas pesquisas epistemológicas e a pedagogia. Partindo-se do pressuposto de que "conhecer um objeto é agir sobre ele e transformá-lo" (Piaget, 1976, p. 37), a educação deverá propiciar um ambiente que estimule o interesse e a iniciativa dos alunos, para que ajam sobre os objetos de estudo.

Piaget (1996, p. 15) defende a presença de "métodos ativos" na educação, que favoreçam a pesquisa espontânea do aluno e exijam "que toda verdade a ser adquirida seja reinventada pelo aluno, ou pelo menos reconstruída e não simplesmente transmitida".

Além da questão da participação ativa dos alunos na construção do conhecimento, a gnosiologia piagetiana envolve a defesa dos trabalhos em grupo, em que os alunos, cooperativamente, desenvolvem pesquisas segundo os seus interesses, apenas auxiliados, coordenados, pelo professor; o que Piaget (1998, p. 111) chama de "self-government".

A cooperação em grupo é fundamental para o epistemólogo porque através dela ocorre a descentração necessária ao desenvolvimento da razão. É interessante notar o paralelo que Piaget traça entre as evoluções do egocentrismo, no plano individual, e do sociocentrismo, no plano coletivo. 
A criança demonstra um egocentrismo intelectual, por exemplo, ao pensar que está sendo seguida pela lua; da mesma forma, o homem primitivo demonstra uma forma de sociocentrismo, por exemplo, quando acredita que o curso dos astros das estações é controlado pela sucessão dos acontecimentos sociais. Para Piaget (1973, p. 83), “permanece um inegável parentesco de estrutura entre estas duas espécies de 'centrismos', em oposição às operações descentradas da razão".

Piaget chega a associar o que ele considera uma forma de "coerção social" (Piaget, 1998, p. 117), de pressão espiritual ou material que um adulto - como, por exemplo, o professor - exerce sobre uma criança, gerando uma forma de respeito unilateral na transmissão de verdades já prontas, aos ritos presentes em tribos primitivas, em que a força da tradição impõe determinados comportamentos, tabus, que devem ser obrigatoriamente aceitos e respeitados.

Para o autor, a cooperação, contrapondo-se à coerção social, é “o conjunto das interações entre indivíduos iguais (por oposição às interações entre superiores e inferiores) e diferenciados (em contraposição ao conformismo compulsório)" (Piaget, 1998, p. 153) que contribui para o desenvolvimento da autonomia, da razão e da socialização.

É inegável a proximidade entre a pedagogia advogada por Piaget e a proposta das Concepções Abertas. A aula aberta, ministrada em co-decisão, que favorece a iniciativa dos alunos, em que o professor é apenas um parceiro no processo de ensino e aprendizagem, é extremamente coerente com a gnosiologia piagetiana.

Após a descrição dos pressupostos gnosiológicos, serão descritos os pressupostos ontológicos piagetianos que estão presentes, mesmo que tacitamente, na proposta da Educação Física em questão.

O primeiro destes pressupostos a ser descrito é a visão de homem que Piaget defende. $\mathrm{O}$ eminente pesquisador considera que as aptidões variam de um indivíduo para outro, o que exige um estado de prontidão para que elas não sejam desperdiçadas ou, ao contrário, sufocadas pela sociedade. Tal 
precaução significa ao mesmo tempo respeito e reconhecimento às diferentes possibilidades de cada ser humano.

$\mathrm{O}$ autor afirma que a educação deveria identificar as aptidões dos alunos para que seu encaminhamento profissional futuro fosse o mais adequado possível. Se, para ele "somente por volta dos 15 anos, em particular, é que se torna possível perceber com certa precisão as aptidões que diferenciam os indivíduos uns dos outros" (Piaget, 1996, p. 40), é necessário, pois, garantir um ensino generalizado de segundo grau até esta idade, deixando em aberto as questões de encaminhamento profissional.

Para Piaget, os psicólogos escolares devem realizar um papel necessário "no diagnóstico e, sobretudo, no prognóstico relativo às aptidões e à orientação dos alunos" (Piaget, 1976, p. 112). O autor está consciente de que tal avaliação "irá comprometer por vezes a carreira e a vida inteira do aluno" (Piaget, 1996, p. 44). Isso demonstra seu conhecimento a respeito dos efeitos nefastos da divisão social do trabalho, presente no modo de produção capitalista.

No modo de produção capitalista, em que vigora a oposição entre trabalhos predominantemente manuais ou corporais-cinestésicos e trabalhos predominantemente intelectuais, os indivíduos estão presos a um determinado ramo de atividade, o que faz com que somente seja possível um desenvolvimento unilateral das potencialidades humanas. O problema é que Piaget, ao invés de elaborar uma pedagogia que se posicione contra tal aviltamento da natureza humana, pelo contrário, partindo do pressuposto ontológico das aptidões individuais, legitima a divisão social do trabalho, assim como as desigualdades sociais dela decorrentes.

Esta questão é referente ao segundo pressuposto ontológico possivelmente identificado na epistemologia piagetiana, qual seja a sua visão de sociedade. Nos seus Estudos sociológicos, o autor analisa a distinção entre direito e moral, que, para ele, ocorre nas sociedades civilizadas, diferentemente das sociedades primitivas nas quais as relações pessoais e transpessoais são muito mais próximas, o que faz com que a regra 
do direito seja menos distinta da regra moral. Dentro desta análise, no que se refere à divisão social do trabalho, ele afirma que:

[...] com o crescimento de volume e de densidade das sociedades, e com a divisão econômica do trabalho e a diferenciação psicológica dos indivíduos, que são suas consequências necessárias, a oposição das relações pessoais e das relações transpessoais se torna cada vez maior (Piaget, 1973, p. 231).

Piaget defende que a divisão social do trabalho ou divisão econômica do trabalho, assim como a diferenciação psicológica dos indivíduos, são consequências "necessárias" do crescimento que torna as sociedades mais complexas. Ambas são, no pensamento piagetiano, leis inelutáveis do progresso.

O problema do discurso da diferenciação psicológica é o significado que adquire quando vinculada à divisão social do trabalho. Para o renomado pesquisador suíço:

As aptidões de um bom médico (o senso clínico, a rapidez do exame visual, o contato com os doentes) são sem dúvida individuais e quase inatas: não se aprendem e são, no máximo, passíveis de desenvolvimento. Mas de nada serviria a um clínico possuí-las se não tivesse se iniciado, durante anos, na anatomia e na fisiologia, na patologia e na clínica. Da mesma maneira, nasce-se pedagogo: ninguém se torna pedagogo e as mais belas lições de metodologia não fornecem o segredo do contato com as crianças a um futuro professor que não gosta delas (Piaget, 1998, p. 181).

Desta forma, pode-se dizer que certos indivíduos, por não possuírem as aptidões "quase inatas" para serem médicos, professores ou engenheiros, nasceram condenados às funções de lixeiros, domésticas ou cortadores de cana. $\mathrm{O}$ fato de as aptidões precisarem ser desenvolvidas não altera o fato de que, para Piaget, elas definem, quando efetivadas, a posição que o indivíduo ocupará na divisão social do trabalho capitalista.

A crítica aos pressupostos piagetianos, aqui já iniciada, prossegue com as contribuições de autores que já identificaram muitos dos problemas presentes no modelo de métodos ativos, defendido, entre outros autores, pelo epistemólogo em questão. 


\section{Crítica aos pressupostos piagetianos}

A concepção pedagógica formulada por Jean Piaget parte dos pressupostos gnosiológicos e ontológicos descritos acima. $\mathrm{O}$ ensino deve ser subjetivado, procurando aproximar-se dos interesses dos alunos, mesmo que para desenvolvê-los. Não são necessárias maiores intervenções do professor - que significariam rupturas nos desejos e nas inclinações inicialmente apresentados pelos discentes - visto que suas aptidões são "quase inatas" e que apenas alguns nascem para exercer um trabalho predominantemente intelectual no futuro. As aptidões devem ser apenas estimuladas, não contrariadas.

Saviani (1989) já demonstrou como a burguesia defendeu o discurso da pedagogia da essência - que, por considerar que todos são essencialmente iguais, defende um ensino igual para todos - quando era a classe revolucionária; entretanto, a partir do momento em que se estabeleceu no poder, o discurso da burguesia passou a ser o da pedagogia da existência, que, ao contrário da pedagogia da essência, enfatiza as diferenças individuais. Sobre a pedagogia da existência, defendida pela burguesia já consolidada como classe dominante, Saviani (1989, p. 52) afirma que:

Com base neste tipo de pedagogia, considera-se que os homens não são essencialmente iguais; os homens são essencialmente diferentes, e nós temos que respeitar as diferenças entre os homens. Então, há aqueles que têm mais capacidade e aqueles que têm menos capacidade; há aqueles que aprendem mais devagar; há aqueles que se interessam por isso e os que se interessam por aquilo.

A intenção do autor não é, evidentemente, a de negar toda e qualquer diferença existente entre os alunos; trata-se, outrossim, de uma crítica à utilização do discurso das diferenças individuais para a legitimação da divisão social do trabalho, que naturaliza as desigualdades sociais, atendendo aos interesses da classe dominante.

Como mostrado anteriormente, a proposta das Concepções Abertas no ensino da Educação Física adota o modelo de métodos ativos, de educação centrada no aluno, tendo Piaget como uma de suas referências. Como ficou 
explícito na fala da professora Gerlinde Glatzer, exposta para ilustrar a proposta, o professor não deve dirigir, prescrever, limitando-se a estimular, aconselhar os alunos, ir ao encontro de suas necessidades. Como escreve Piaget (1996, p. 15), “o educador continua indispensável, a título de animador".

Não se trata de imputar às Concepções Abertas o rótulo de construtivista, até porque, como lembra Rossler (2000, p. 07) “a definição de construtivismo é problemática até mesmo entre os próprios construtivistas".

A questão é que a proposta das Concepções Abertas, por estar presa aos parâmetros piagetianos da subjetivação do ensino, apresenta sérias limitações, como será tratado a seguir.

Snyders, por exemplo, é um dos autores que rompem com as visões de homem, de educação e de sociedade piagetianas. Sobre a questão dos interesses dos alunos, relacionada às intervenções do professor, o autor afirma:

[...] pessoalmente, eu penso que o desejo da criança não é a voz da natureza; o desejo da criança é o resultado do seu modo de vida; é a resultante de muitas influências que sobre ela se exercem: em grande parte, o desejo está em relação com a classe social da criança. Os filhos de operários indiferenciados não têm imediatamente os mesmos desejos que os filhos dos engenheiros ou dos médicos. O desejo de estudar álgebra não se reparte igualmente por toda a população (Snyders, 1984, p. 19).

Partindo-se deste pressuposto, maiores intervenções do professor são necessárias para que os alunos ultrapassem seus desejos primeiros, que são sobremaneira condicionados por sua classe social.

Como o saber elaborado é mais complexo que as informações que os alunos assimilam no dia-a-dia, como a linguagem erudita é estranha às crianças - principalmente às das camadas populares -, é fundamental um espaço privilegiado para que o professor exerça a sua competência pedagógica, através da qual são combatidas certas limitações nos desejos iniciais dos alunos, que os afastam de certos conteúdos, e, no caso daqueles 
mais carentes, podem condená-los às funções mais subalternizadas pela divisão social do trabalho capitalista.

É necessário um ensino na Educação Física que tenha como objetivo aproximar ao máximo os alunos do saber elaborado, universalmente produzido, acerca da cultura corporal.

Neste sentido, é possível dizer que a proposta das Concepções Abertas é limitada porque seus formuladores não fazem a reflexão de que, por influência do contexto social, um determinado conteúdo pode requerer uma intervenção do professor que ultrapasse os parâmetros da aula aberta.

Por exemplo, é de se duvidar que uma aula de dança, ministrada a alunos de escolas públicas brasileiras, seja construída com uma reduzida intervenção do professor. Isto principalmente no que se refere à participação dos meninos, devido aos preconceitos ainda existentes quanto à prática deste patrimônio da cultura corporal pelo sexo masculino.

Quando o conteúdo já agrada aos alunos, é bem possível que o professor possa apenas coordenar muitos momentos da aula - como, por exemplo, no ensino do futebol em uma aula de Educação Física, no Brasil. Entretanto, quando se trata de romper com um gosto já adquirido e que, como no exemplo dado, carrega preconceitos, a questão torna-se um problema.

O exemplo dado, apesar de já ter sido sobejamente discutido no meio acadêmico da Educação Física, é fundamental para questionar a contradição, operada pelas Concepções Abertas, entre professor e alunos. Ao romper com o preconceito - como no caso supracitado - e favorecer a vivência da dança pelos alunos, o professor, por mais que intervenha, dirija e delimite certos parâmetros de ação dos alunos, proporcionará a eles experiências que muitas vezes não adquiririam fora da escola, onde estavam limitados a certas práticas corporais, e, em parte, condicionados por ideias e valores vigentes. Neste caso, uma intervenção, mesmo que intensa, por parte do professor, não representa, num certo sentido, o aprisionamento das subjetividades dos alunos, mas a sua libertação. 
Apesar de afirmar a necessidade de se refletir sobre as ideias e valores que permeiam os elementos da cultura corporal, os autores da proposta das Concepções Abertas, por enfatizarem uma intervenção reduzida do professor, comprometem os espaços em que a competência pedagógica do mesmo será exercida. Pode-se levantar a questão de como o professor deveria agir no caso de, na co-decisão dos conteúdos, a maioria dos alunos se opor à dança. Defender a imposição de um conteúdo parece comprometer a subjetivação do ensino; entretanto, sem a dimensão do rompimento com os interesses já adquiridos pelos alunos - que se desenvolvem em relação dialética com as ideias e valores vigentes - é a própria especificidade do ato pedagógico que está comprometida.

Além disso, está ausente na proposta das Concepções Abertas a possibilidade do professor de Educação Física poder atuar, procurando desenvolver nos alunos o gosto pelo estudo dos clássicos, o prazer de saber como eram os Jogos Olímpicos na Antiguidade Grega, o significado social do aprendizado da natação no Império Romano, ou o sentido que Hitler deu às Olimpíadas de 1936, realizadas na Alemanha nazista, por exemplo.

Em síntese, ao restringir as intervenções do professor, a proposta das Concepções Abertas compromete a dimensão do rompimento das inclinações iniciais dos alunos. Isto é bastante problemático, porque tal rompimento é necessário para o desabrochar do gosto por novos conteúdos, sem os quais os alunos mais carentes estão em desvantagem em relação àqueles que já crescem num meio social que lhes fornece os estímulos para a assimilação de diversos patrimônios culturais - no caso da Educação Física, os temas da cultura corporal; o que constitui uma questão políticopedagógica muito séria.

\section{Considerações finais}

Em virtude da análise aqui empreendida, é possível identificar como os pressupostos gnosiológicos e ontológicos do pensamento piagetiano influenciaram, de forma mais ou menos consciente, a elaboração da proposta das Concepções Abertas no ensino da Educação Física. 
É importante enaltecer as contribuições da proposta para a área em questão, no que se refere, por exemplo, à superação do ensino de gestos esportivos padronizados. Não obstante, é possível identificar nela limitações por estar presa aos parâmetros piagetianos da subjetivação do ensino, que comprometem o espaço em que o professor pode exercer a sua competência pedagógica.

O ensino da Educação Física deve buscar despertar nos alunos o gosto pelo conhecimento dos clássicos da cultura corporal, e aflorar carências adormecidas pela falta de estímulos, o que constitui uma lacuna nas Concepções Abertas, embora isto não a desqualifique como uma das mais importantes propostas para esta área de estudo.

\section{Referências}

GLATZER, G. Série de aulas: nós inventamos jogos. In: HILDEBRANDTSTRAMANN, R. e LAGING, R. Concepcões Abertas no ensino da Educação Física. Rio de Janeiro: Ao Livro Técnico, 1986.

HILDEBRANDT-STRAMANN, R. Experiência: uma categoria central na teoria didática das aulas abertas. In: CHAVES, M. (Org.). Pedagogia do movimento: diferentes concepções. 2. ed. Maceió: EDUFAL, 2004.

HILDEBRANDT-STRAMANN, R. Textos pedagógicos sobre o ensino da Educação Física. 3 ed. Ijuí: Ed. Unijuí, 2005.

HILDEBRANDT-STRAMANN, R. e LAGING, R. Concepcões Abertas no ensino da Educação Física. Rio de Janeiro: Ao Livro Técnico, 1986.

LIRA NETO, J. F. de. Relações entre a proposta das Concepções Abertas no ensino da Educação Física e o método Paulo Freire. In: Revista Conexões, Campinas, v. 6, n. 2, p. 62-81, 2008.

PIAGET, J. Estudos sociológicos. Rio de Janeiro: Editora Forense, 1973.

PIAGET, J. Psicologia e pedagogia. 4. ed. Rio de Janeiro: Editora Forense, 1976.

PIAGET, J. Para onde vai a educação? 13. ed. Rio de Janeiro: José Olympio, 1996.

PIAGET, J. A evolução social e a pedagogia nova. In: PIAGET, J. Sobre a pedagogia. São Paulo: Casa do Psicólogo, 1998.

PIAGET, J. Observações psicológicas sobre o self-government. In: PIAGET, J. Sobre a pedagogia. São Paulo: Casa do Psicólogo, 1998. 
PIAGET, J. A educação da liberdade. In: PIAGET, J. Sobre a pedagogia. São Paulo: Casa do Psicólogo, 1998.

PIAGET, J. A pedagogia moderna. In: PIAGET, J. Sobre a pedagogia. São Paulo: Casa do Psicólogo, 1998.

ROSSLER, J. H. Construtivismo e alienação: as origens do poder de atração do ideário construtivista. In: DUARTE, N. (Org.). Sobre o construtivismo: contribuições a uma análise crítica. Campinas, SP: Autores Associados, 2000.

SÁNCHEZ GAMBOA, S. A. Epistemologia da Educação Física: as inter-relações necessárias. Maceió: EDUFAL, 2007.

SAVIANI, D. Escola e democracia: teorias da educação, curvatura da vara, onze teses sobre educação e política. 21. ed. São Paulo: Cortez: Autores Associados, 1989.

SNYDERS, G. As pedagogias não-directivas. In: SNYDERS, G.; LEON, A.; GRÁCIL, R. Correntes actuais da pedagogia. Lisboa: Livros Horizonte, 1984. 